\title{
Disrupted white matter structural networks in healthy older adult APOE $\varepsilon 4$ carriers - An International Multicenter DTI Study
}

Enrica Cavedo 1,2, Simone Lista 1, Katrine Rojkova ${ }^{1}$, Patrizia Andrea Chiesa', Marion Houot ${ }^{3}$, Katharina Brueggen ${ }^{4}$, Janusch Blautzik ${ }^{5}$, Arun L.W. Bokde ${ }^{6}$, Bruno Dubois ${ }^{7}$, Frederik Barkhof ${ }^{8}$, Petra J.W. Pouwels ${ }^{8}$, Stefan Teipel ${ }^{4,9}$ and Harald Hampel ${ }^{1}$

for the Alzheimer Precision Medicine Initiative (APMI)

${ }^{1}$ AXA Research Fund \& UPMC Chair, Sorbonne Universités, Université Pierre et Marie Curie (UPMC) Paris 06, Inserm, CNRS, Institut du Cerveau et de la Moelle Épinière (ICM), Département de Neurologie, Institut de la Mémoire et de la Maladie d'Alzheimer (IM2A), Hôpital Pitié-Salpêtrière, Boulevard de l'hôpital, F-75013, Paris, France ;

2 Laboratory of Alzheimer's Neuroimaging and Epidemiology, IRCCS Centro San Giovanni di Dio Fatebenefratelli, Brescia, Italy;

${ }^{3}$ Institute of Memory and Alzheimer's Disease (IM2A), Centre of excellence of neurodegenerative disease (CoEN), ICM, APHP Department of Neurology, Hopital Pitié-Salpêtrière, University Paris 6, Paris, France ${ }^{4}$ DZNE, German Center for Neurodegenerative Diseases, Rostock, Germany

${ }^{5}$ Institute for Clinical Radiology, Department of MRI, Ludwig Maximilian University Munich

${ }^{6}$ Cognitive Systems Group, Discipline of Psychiatry, School of Medicine, Trinity College Dublin, Dublin, Ireland; and Trinity College Institute of Neuroscience (TCIN), Trinity College Dublin, Dublin, Ireland ${ }^{7}$ Sorbonne Universities, Pierre et Marie Curie University, Paris 06, Institute of Memory and Alzheimer's Disease (IM2A) \& Brain and Spine Institute (ICM) UMR S 1127, Departament of Neurology, Hopital PitiéSalpêtrière, Paris, France

${ }^{8}$ Department of Radiology and Nuclear Medicine, Neuroscience Campus Amsterdam, VU University Medical Centre, The Netherlands

${ }^{9}$ Department of Psychosomatic Medicine, University Medicine Rostock, Rostock, Germany

*Corresponding authors: Enrica Cavedo and Harald Hampel, Université Pierre et Marie Curie, Paris 06, Département de Neurologie, Institut de la Mémoire et de la Maladie d'Alzheimer (IM2A), Hôpital de la Salpêtrière, 47 Bd de l'hôpital, 75013 Paris, France - Tel +33 (0)1 572747 24, enrica.cavedo@gmail.com; harald.hampel@icm-institute.org; harald.hampel@med.uni-muenchen.de 


\section{Abstract}

The $\varepsilon 4$ allelic variant of the Apolipoprotein $\mathrm{E}$ gene $(A P O E \varepsilon 4)$ is the best-established genetic risk factor for late-onset Alzheimer's disease (AD). White matter (WM) microstructural damages measured with Diffusion Tensor Imaging (DTI) represent an early sign of fiber tract disconnection in AD. We examined the impact of $A P O E \varepsilon 4$ on WM microstructure in elderly individuals from the multicenter European DTI Study on Dementia. Voxelwise statistical analysis of Fractional anisotropy (FA), mean diffusivity, radial and axial diffusivity (MD, radD and axD respectively) was carried out using Tract-Based Spatial Statistics. Seventyfour healthy elderly individuals - 31 APOE $\varepsilon 4$ carriers ( $A P O E \varepsilon 4+)$ and 43 APOE $\varepsilon 4$ non-carriers ( $A P O E$ $\varepsilon 4-)$-were considered for data analysis. All the results were corrected for scanner acquisition protocols, age, gender and for multiple comparisons. APOE $\varepsilon 4+$ and $A P O E \varepsilon 4$ - subjects were comparable regarding sociodemographic features and global cognition. A significant reduction of FA and increased radD was found in the APOE $\varepsilon 4+$ compared to the $A P O E \varepsilon 4$ - in the cingulum, in the corpus callosum, in the inferior fronto-occipital and in the inferior longitudinal fasciculi, internal and external capsule. APOE $\varepsilon 4+$, compared to $A P O E \varepsilon 4$ - showed higher $M D$ in the genu, right internal capsule, superior longitudinal fasciculus and corona radiate. Comparisons stratified by center supported the results obtained on the whole sample. These findings support previous evidence in monocentric studies indicating a modulatory role of $A P O E \& 4$ allele on WM microstructure in elderly individuals at risk for $A D$ suggesting early vulnerability and/or reduced resilience of WM tracts involved in AD.

Keywords : Diffusion Tensor Imaging; Apolipoprotein E; multicenter study; White Matter Integrity; Aging 


\section{INTRODUCTION}

The APOE gene, located on chromosome 19q13.2, encodes for the ApoE protein (Boyles et al., 1985, Nakai et al., 1996). ApoE participates in lipid metabolism, particularly in cholesterol transport and clearance. Moreover, its activity is associated with relevant components of brain WM such as myelin, of which cholesterol is a major constituent (Westlye et al., 2012). It is also implicated in neuronal growth and repair, nerve regeneration, immune response, and activation of lipolytic enzymes (Karch et al., 2014, Yu et al., 2014). At present, the $\varepsilon 4$ allelic variant of $A P O E-A P O E \varepsilon 4$ - is the best established genetic risk factor for the development of late-onset Alzheimer's Disease (AD) (Corder et al., 1993, Strittmatter et al., 1993). The involvement of genetic risk factors such as APOE $\varepsilon 4$ in sporadic late-onset $A D$ has been profoundly demonstrated (Saunders et al., 1993, Sherrington et al., 1995, Bertram et al., 2007, Reitz et al., 2011, Lockhart and DeCarli, 2014).

Structural neuroimaging patterns related to $A P O E \varepsilon 4$ in elderly individuals described grey matter atrophy in the medial temporal structures (Chen et al., 2007, Donix et al., 2010b, Hua et al., 2010, Risacher et al., 2010, Lu et al., 2011, Roussotte et al., 2014) such as the subiculum (Burggren et al., 2008, Suthana et al., 2010) and CA1 subfield (Kerchner et al., 2014) of the hippocampus (Donix et al., 2010a, Chiang et al., 2011, O'Dwyer et al., 2012, Taylor et al., 2014), although contrasting results were published as well (Jack et al., 1998, Du et al., 2006, Schuff et al., 2009, Taylor et al., 2014). Moreover, higher cortical betaamyloid deposition (Reiman et al., 2009, Morris et al., 2010, Fleisher et al., 2013), glucose hypometabolism in brain regions typically impaired in AD (Rimajova et al., 2008, Protas et al., 2013, Fouquet et al., 2014) and changes in brain function during an encoding memory task (Filippini et al., 2011) were previously described in elderly cognitive intact individuals carrying the $A P O E \varepsilon 4$ allele. No interaction effects were found of APOE $\varepsilon 4$ status on the relationship between brain beta-amyloid levels and grey matter network disruption (Tijms et al., 2016). So far, the exact pathophysiological mechanism through which $A P O E \varepsilon 4$ contributes to the aetiology and progression of the disease remains unclear.

In vitro and in vivo studies demonstrated that $A P O E \varepsilon 4$ allele is associated with axonal degeneration (Tesseur et al., 2000) and structural modifications in intracellular microtubules (Nathan et al., 1995), thereby raising the possibility of mechanistically impacting white matter (WM) microstructure (Heise et al., 2011, Westlye et al., 2012, Heise et al., 2014). More than half of the individuals diagnosed with AD display WM microstructural alterations (Chalmers et al., 2005) that can be investigated in vivo by diffusion tensor imaging (DTI).

DTI detects the amplitude and directional coherence of water molecule diffusion and, since water molecule diffusion is usually constrained along the main fiber direction by axonal membranes and myelin sheaths, this feature can be used to measure WM structural integrity (Pierpaoli and Basser, 1996, Behrens et al., 2007). In particular, Fractional Anisotropy (FA) measures are generally high in healthy, structurally intact, coherently organized WM tissues (Acosta-Cabronero and Nestor, 2014). However, 
there was also evidence of reduced FA in healthy cognitively intact adults in region of crossing fibers between the corticospinal tract and the superior longitudinal fasciculus (Douaud et al., 2011) as previously reported also in diseased tissue (Amlien and Fjell, 2014).

Whereas, high Mean Diffusivity (MD), Radial Diffusivity (radD) and Axial Diffusivity (axD) measures may potentially be used to detect tissue breakdown, myelin loss and axonal injury respectively (Beaulieu, 2002, Song et al., 2002, Song et al., 2005, Kumar et al., 2011, Kumar et al., 2013).

Previous studies investigating DTI indexes in AD patients showed a consistent pattern of decreased FA and increased $M D$, radD and axD, suggesting the presence of WM tracts disconnection in this population (Amlien and Fjell, 2014, Zhang et al., 2014). Although brain WM integrity, in older adults carrying APOE $\varepsilon 4$, have been previously investigated in several monocentric studies (Gold et al., 2012, Felsky and Voineskos, 2013, Lyall et al., 2014), the reproducibility of these results in multicenter studies has not been sufficiently examined. In the present study, we investigated how the APOE $\varepsilon 4$ variant alters the brain WM microstructure in healthy older individuals recruited in the European multicenter DTI Study on Dementia (EDSD). 


\section{EXPERIMENTAL PROCEDURES}

\section{Participants}

Sociodemographic, clinical and neuroimaging data were selected from the retrospective multicenter European Diffusion Tensor Imaging Study on Dementia (EDSD) database (Teipel et al., 2011, Fischer et al., 2012, Teipel et al., 2012, Dyrba et al., 2013, Dyrba, 2014, Kilimann et al., 2014, Kljajevic et al., 2014, Teipel et al., 2014, Tsao et al., 2014, Brueggen et al., 2015, Dyrba et al., 2015, Brueggen et al., 2016). The EDSD is a framework created to study the multicenter variability and diagnostic accuracy of DTI derived markers in patients with prodromal Alzheimer's disease (AD) and AD dementia. It was founded in 2010 and is coordinated by the German Center for Neurodegenerative Diseases (DZNE) in Rostock (Germany). Initially, MRI data, including DTI sequences of healthy control subjects (HC) and AD patients were retrospectively collected from 10 European centers leading in the field of AD research. The EDSD database has collected data from eleven European centers: Amsterdam (The Netherlands), Brescia (Italy), Cambridge (United Kingdom), Dublin (Ireland), Frankfurt (Germany), Freiburg (Germany), Milan (Italy), Mainz (Germany), Mannheim (Germany), Munich (Germany), and Rostock (Germany). As of March 2016, the EDSD sample consists of 139 Alzheimer's patients, 160 Mild Cognitive Impairment patients and 194 Healthy controls. An inclusion criterion for each center in order to upload the data of HC required that they were free of cognitive complaints-impairment. Healthy subjects were recruited via advertisement, e.g. in newspapers. During anamnesis and neuropsychological assessment it was ruled out that they had cognitive complaints or medical diseases, including neurological and psychiatric diseases (such as depression or substance abuse). In the present study, we selected 85 healthy control individuals that underwent $A P O E$ genotyping conducted according to the standard methods derived from Amsterdam (renamed Center 1), Dublin (Center 2), Munich (Center 3), and Rostock (Center 4). Quality control of DTI scans was done visually to exclude scans with conspicuous artefacts such as ghosting, blurring due to motion, or strong susceptibility artefacts, and scans on which the brain was not entirely delimited within the field of view. Because of poor/incomplete head coverage preventing the creation of the mean FA image and its skeleton, 20 DTI scans were excluded from the analysis. The sample was subsequently enriched by integrating 9 supplementary DTI scans of individuals carrying APOE \&4 coming from Rostock center. The analysis was carried out on 74 healthy cognitively normal older individuals categorized into 31 $A P O E \varepsilon 4$ carriers (APOE $\varepsilon 4+$ ) and 43 APOE $\varepsilon 4$ non-carriers (APOE $\varepsilon 4-)$. All procedures followed were in accordance with the ethical standards of the responsible committee on human experimentation (institutional and national) and with the Helsinki Declaration of 1975, and the applicable revisions at the time of the investigation. The study was approved by the local ethics committee in each participating center. Written informed consent was provided from all participants or their representatives. 


\section{Image Acquisition}

Images were acquired using four different magnetic resonance imaging (MRI) scanners. The detailed image acquisition protocol has been described in Table 1 while Figure 1 report a representative FA map for each site. Because of a possible effect of the scanner type on the data, centers were treated as covariates in the statistical analysis.

\section{TBSS Image Processing and atlas-based ROI analyses}

The DTI toolbox of FSL (4.1) (available at http://www.fmrib.ox.ac.uk/fsl/) was used for the DTI data preprocessing. Voxelwise statistical analysis of the FA data was carried out using TBSS (Tract-Based Spatial Statistics (Smith et al., 2004)), part of FSL (Smith, 2002). First, FA images were created by fitting a tensor model to the raw diffusion data using FDT, and then brain-extracted using BET (Smith, 2002). All subjects' FA data were then aligned into a common space using the nonlinear registration tool FNIRT (www.fmrib.ox.ac.uk/analysis/techrep), which uses a b-spline representation of the registration warp field (Rueckert et al., 1999). Next, the mean FA image was created and thinned to create a mean FA skeleton, thresholded at FA $>0.2$, which represents the centres of all tracts common to the group. Each subject's aligned FA data were then projected onto the skeleton. In addition, the nonlinear warps and the skeleton projection achieved with FA images were applied to the MD, radD and axD maps to bring them into standard space (Jovicich et al., 2014). Finally, data fed into voxelwise cross-subject statistics.

Moreover, an atlas-based $\mathrm{ROI}$ analysis for $\mathrm{FA}, \mathrm{MD}$ and radD maps was performed in the WM tracts resulted significance from voxelwise cross-subject statistics. In particular, we focused on the corpus callosum (genu, body and splenium), the internal and external capsule, the inferior fronto-occipital and inferior longitudinal fasciculi, the cingulum, the right corona radiate, the right posterior thalamic radiation and the right superior longitudinal fasciculus. These WM ROIs are pre-defined in the JHU-ICBM-FA-1mm atlas. We back-projected the ROIs with a non-linear co-registration to each subject's FA map in the MNI152 space obtained from TBSS. Each ROI label was overlapped with the FA TBSS skeleton space to remove any CSF and gray matter voxels. These new ROls were then used in each subject's FA, MD and radD maps (MNI152 space) to extract the FA, MD and radD metrics in each above mentioned tract (Jovicich et al., 2014). Subject motion, was extracted from each DTI acquisition using the tool FLIRT from FSL (Jenkinson et al., 2002). 


\section{Statistical Analysis}

\section{Demographic, clinical, cognitive data, global and tracts related FA, MD, radD, and axD mean values}

Group differences between APOE $\varepsilon 4+$ and APOE $\varepsilon 4$ - were assessed using the Chi-Square test for categorical variables and using the Mann-Whitney U-test for continuous variables. For global and tracts related FA, MD, radD and axD mean values as well as motion, group differences were adjusted for site, age and gender using linear regression. At first, the group by age interaction was added in the linear models and it was tested for global and specific WM tracts. The interaction was removed when no significant effect was detected. Effects were tested using likelihood ratio test. $P$ values were corrected for multiple testing using Benjamini-Hochberg correction. Cohen's $f^{2}$ was used to measure the effect size of ApoE4 status for global metrics and specific WM tracts. Moreover, stratification by centers was performed to assess group differences in DTI global metrics. For this analysis Mann-Whitney U-test was used and the effect size was calculate as proposed by Cohen (Cohen 1988) according to the following formula: $\mathrm{z} / \mathrm{sqrt}(\mathrm{N})$. P values were corrected for multiple testing using Benjamini-Hochberg correction. Statistical analysis was performed using $R$ 3.3.2.

TBSS: General Linear Model. First, design matrix and contrast for the General Linear Model were generated including center, gender and age as covariate (Number of EVs: 7, Number of Points: 74, Number of Contrasts: 2). Then, voxelwise statistics of DTI images were performed using the randomise FSL's tool for nonparametric statistical thresholding (Nichols and Holmes, 2002) using the Threshold-Free Cluster Enhancement option. The number of permutations was set at 5000 (Nichols and Holmes, 2002). $\mathrm{MD}, \mathrm{FA}$, axD, and radD values within the skeleton were compared between APOE $\varepsilon 4+$ and APOE $\varepsilon 4-$ groups controlling for the family-wise error (FWE) rate (two tailed, $p<0.05$ ). We then compared MD, FA, axD, and radD values between APOE $\varepsilon 4+$ and APOE $\varepsilon 4$ - groups within each single center (two tailed $p<$ 0.05). 


\section{RESULTS}

\section{Clinical, demographic, and neuropsychological findings}

In the non-carrier group the allelic frequencies for APOE were: $\varepsilon 2 / \varepsilon 3=7 \quad \varepsilon 3 / \varepsilon 3=36$, while in the carrier group were: $\varepsilon 2 / \varepsilon 4=5 ; \varepsilon 3 / \varepsilon 4=23 ; \varepsilon 4 / \varepsilon 4=3$. Subject groups did not differ in terms of age at MRI date, sex, education, and global cognition measured using the MMSE, both considering the whole sample (Table 2) and the stratification by single center (Table 3).

\section{Comparisons of DTI Indexes: FA, MD, radD, axD}

DTI metrics were not influenced by subject motion, as described by rotation parameters reported in Table 2. Comparison between APOE $\varepsilon 4+$ and APOE $\varepsilon 4$ - in terms of global FA, MD, radD, and axD mean values revealed significant results exclusively for $\mathrm{FA}$ and radD. A significant $\mathrm{FA}$ reduction and increase radD in APOE $\varepsilon 4+$ compared to APOE $\varepsilon 4$ - was observed (FA: $p<0.001$, Cohen $f=0.31 ; \operatorname{radD}: \mathrm{p}<0.001$, Cohen $f$ $=0.31$, Table 2). The comparison within centers showed a significant reduction of FA in the APOE $\varepsilon 4+$ compared with the APOE $\varepsilon 4$ - cases in Center $4(p=0.024 r=0.55$, Table 3$)$, while an increase of axD was found in Center $2(p=0.028 r=0.70)$ and an increase of radD was detected exclusively in Center 4 ( $p=0.007$ Cohen $r=0.70$, Table 3 ). The distribution of DTI metrics across centers is described in the Figure 2. No significant group*age interaction was found for $F A, M D, \operatorname{axD}$, radD (Table A1).

\section{TBSS: Decreased Fractional Anisotropy (FA), in APOE ع4+ vs. APOE ع4-}

Compared with APOE $\varepsilon 4-$, individuals with APOE $\varepsilon 4+$ showed significant widespread reduction of FA across the entire skeleton (Figure 3 ). In particular, major differences between the two groups were located in all components of corpus callosum: genu $(p<0.001$, Cohen $f=0.44)$, body $(p=0.001$, Cohen $f=0.17)$ and splennium ( $p<0.001$, Cohen $f=0.37$, Table A2), bilaterally in the internal capsule (right: $p<0.001$, Cohen $f=0.68$; left: $\mathrm{p}<0.001$, Cohen $f=0.47$, Table A2), in the right and left external capsule (right: $\mathrm{p}<$ 0.001 , Cohen $f=0.27$; left: $\mathrm{p}=0.003$, Cohen $f=0.15$, Table A2), bilaterally in the inferior fronto-occipital and inferior longitudinal fasciculi (right: $\mathrm{p}=0.004$, Cohen $f=0.13$; left: $\mathrm{p}=0.009$, Cohen $f=0.11$, Table A2), and in the cingulum (right: $p<0.001$, Cohen $f=0.33$; left: $p=0.015$, Cohen $f=0.10$, Table A2) particularly its anterior part (Figure 3). Table A2 reports p-values for group differences of specific FA white tracts. No significant group*age interaction was found for all white matter tracts considered (Table A1).

Subsequently, the analysis was repeated separately for each center. After controlling for the family-wise error, results remained significant only for Center $4(p<0.05)$. However, the uncorrected $p$-maps showed a similarly widespread reduction of FA within each center (Figure 4). No effects in FA in the opposite direction, i.e. increased FA in APOE $\varepsilon 4+$ vs APOE $\varepsilon 4-$, were found; even when uncorrected p-values were scrutinized.

TBSS: Increased Mean Diffusivity, in APOE $\varepsilon 4+$ vs. APOE $\varepsilon 4-$ 
Compared with APOE $\varepsilon 4-$, individuals with APOE $\varepsilon 4+$ showed significant increase of MD in the right hemisphere (Figure 5), particularly in the genu of corpus callosum ( $p=0.002$, Cohen $f=0.16$, Table A2), in the right internal capsule $(p=0.004$, Cohen $f=0.13$, Table A2) in the right corona radiate $(p=0.016$, Cohen $f=0.09$, Table A2) and in the right superior longitudinal fasciculus ( $p=0.020$, Cohen $f=0.08$, Table A2). No significant group*age interaction was found for all white matter tracts considered (Table A1). Subsequently, the analysis was repeated separately for each center. After controlling for the family-wise error, results remained significant only for Center $4(p<0.05)$ (Figure 6). However, the uncorrected $p$ maps showed similar MD maps within each center (Figure 6). No effects in MD in the opposite direction, i.e. increased FA in APOE $\varepsilon 4+$ vs APOE $\varepsilon 4-$, were found; even when uncorrected $p$-values were scrutinized.

\section{TBSS: Increased Radial Diffusivity (radD), in APOE ع4+ vs. APOE ₹4-.}

An increase in radD was found in APOE $\varepsilon 4+$ compared to APOE $\varepsilon 4-$ (Figure 7), in particular in the genu and splenium of corpus callosum $(p<0.001$, Cohen $f=0.41$ and $p<0.001$, Cohen $f=0.33$ respectively, Table A2), bilaterally in the internal capsule (right: $p<0.001$, Cohen $f=0.65$; left: $p<0.001$, Cohen $f=$ 0.57 , Table A2), in the right and left inferior fronto-occipital and inferior longitudinal fasciculi (right: $p<$ 0.001 , Cohen $f=0.24$; left: $p<0.001$, Cohen $f=0.22$, Table A2), in the anterior and posterior part of the cingulum bilaterally (right: $\mathrm{p}<0.017$, Cohen $f=0.89$; left: $\mathrm{p}<0.004$, Cohen $f=0.13$, Table A2) and in the external capsule bilaterally (right: $p<0.001$, Cohen $f=0.89$; left: $p<0.003$, Cohen $f=0.13$, Table A2) (Figure 7). No significant group*age interaction was found for all white matter tracts considered (Table A1). Statistical comparisons within centers revealed a significantly increased radD in the APOE $\varepsilon 4+$ group in the Center 4 (Figure 8). Centers 1, 2, and 3, uncorrected p-maps revealed a trend of increased radD in the APOE $\varepsilon 4+$ compared to APOE $\varepsilon 4$ - (Figure 8). No increased in radD was observed in the APOE $\varepsilon 4-$ group relative to the APOE $\varepsilon 4+$, even when uncorrected $p$-values were scrutinized. 


\section{DISCUSSION}

In the present study, we explored the impact of the $A P O E \& 4$ genotype on WM microstructure in cognitively intact older adults recruited in the EDSD multicenter study. To our knowledge this is the first multicenter study investigating a broad range of WM microstructure indices on a population of cognitively healthy elderly individuals. Indeed, the majority of studies published so far on the effect of $A P O E \varepsilon 4+$ on the WM microstructure in cognitively intact older individuals have previously explored exclusively FA and MD indices, while the present study has also considered radD, and axD indices. Our results showed FA reduction and concomitant higher $\mathrm{MD}$ and radD in brain areas affected by $\mathrm{AD}$. No significant differences in axD were found between $A P O E \varepsilon 4+$ and $A P O E$ \&4-. In addition APOE $\varepsilon 4$ - cases showed no decrease of FA or increase of MD and radD in any tract compared to $A P O E \varepsilon 4+$ cases.

Several evidences have showed an increased risk to develop AD in elderly individuals carrying APOE $\varepsilon 4$. In particular, evidence have reported in APOE $\varepsilon 4$ heterozygotes individuals compared to APOE $\varepsilon 3$ homozygotes a risk of developing $A D$ of 4 times higher above 60 years old (Reinvang et al., 2013). Furthermore, previous studies described how cognitive intact and mild cognitive impairment individuals carrying APOE $\varepsilon 4$ compared to APOE $\varepsilon 4$ non-carriers had an increase of brain beta-amyloid and tau load (Reiman et al., 2009, Small et al., 2009, Morris et al., 2010), the two major pathophysiological hallmarks of AD. This evidence highlights the importance of investigating indices of white matter microstructure related to population of older age adults at high risk to develop AD.

Despite our data were collected at mutlicentric level in a non-homogenized clinical settings using different DTI acquisition protocols, our findings are generally consistent with previous DTI studies, showing alterations of cerebral WM in elderly APOE $\varepsilon 4+$ compared with APOE $\varepsilon 4$ - individuals (Persson et al., 2006, Smith et al., 2010, Heise et al., 2011, Ryan et al., 2011). We found a lower WM integrity in individuals carrying $A P O E \& 4$ in WM tracts characteristically associated with early $A D$ pathology, such as the corpus callosum, the cingulum, and the inferior longitudinal and fronto-occipital fasciculi (Medina et al., 2006, Rose et al., 2006, Xie et al., 2006, Firbank et al., 2007, Huang et al., 2007, Sydykova et al., 2007, Teipel et al., 2007, Filippini et al., 2009, Tsao et al., 2014, Lee et al., 2016). In particular, in agreement with previous evidence, we found lower FA and higher radD values in $\varepsilon 4$ carriers compared to non-carriers in the genu and splenium of corpus callosum (Persson et al., 2006, Smith et al., 2010, Ryan et al., 2011, Adluru et al., 2014, Tsao et al., 2014, Lee et al., 2016). This finding also agrees with prior MRI studies observing macroscopic WM lesions in both normal aging (Bartzokis, 2004, Filippini et al., 2009) and AD patients (Janowsky et al., 1996, Teipel et al., 2003) in the corpus callosum. Morphological differences in the corpus callosum may point to regional and cell-type specific neuronal neurodegeneration (Hampel et al., 1998); indeed, WM fibres of the splenium originate from the temporoparietal regions (Conturo et al., 1999), which are characteristically affected in the early stages of AD (Thompson et al., 2001, Ewers et al., 2011a).

In agreement with previous studies, using the same method, we found a significant widespread reduction of FA in the posterior portion of cingulum, in the inferior fronto-occipital and longitudinal fasciculi in elderly 
non-demented APOE $\varepsilon 4+$ participants (Heise et al., 2011, Zhang et al., 2015).

In line with previous literature results, cognitive intact individuals carrying APOE $\varepsilon 4$ showed a significant increase of MD in the genu of corpus callosum (Heise et al., 2011), in the corona radiata, internal capsule and superior longitudinal fasciculus (Heise et al., 2011, Westlye et al., 2012, Adluru et al., 2014). A study conducted on a smaller sample of elderly individuals carrying APOE $\varepsilon 4$ from the EDSD database (Kljajevic et al., 2014) reported a modest effect of $A P O E \varepsilon 4$ on $M D$ in the lentiform nucleus in healthy controls comparing $A P O E \varepsilon 4+$ with $A P O E \varepsilon 4-$. The number of overlapping subjects between the present work and the one of Kljajevic and colleagues was 35 out of 74 subjects considered in the present Manuscript. These inconsistent DTI findings may be partially due to the small sample size and the use of different methods (such as FSL, SPM).

In addition, a significantly increased radD in elderly $A P O E \varepsilon 4+$ individuals was detected. Few studies investigating this marker in $A P O E \varepsilon 4$ carriers have been conducted so far. Our results are in line with the findings described in the manuscript by Westlye and colleagues (2012), showing an increased radial diffusivity in $A P O E \varepsilon 4+$ compared to $A P O E \varepsilon 4$-. Interestingly, preliminary results showed an increase of radial diffusivity in elderly individuals at risk of $A D$, defined as the presence of APOE $\varepsilon 4$ and family history of dementia, thus raising the possibility that reduced WM integrity may contribute to AD onset (Ewers et al., 2011b, Gold et al., 2012). Decreased FA and increased radD were found in the inferior longitudinal fasciculus indicates a substantial involvement of WM fibres connecting the occipital and medial temporal lobe regions (Catani et al., 2003), including the amygdala/hippocampal head regions anteriorly and the ventral visual association areas posteriorly. It is well known that these tracts - involved in face recognition (Fox et al., 2008), visual perception (ffytche and Catani, 2005) and visual memory processing (Ross, 2008) - are affected in AD (Liu et al., 2011). Furthermore, a recent study showed as healthy elderly APOE $\varepsilon 4+$ carriers exhibited topographical alterations in both WM and functional networks, in particular with a reduced efficiency in the parahippoacampal gyrus mediated by the effect of APOE variants on memory performances (Chen et al., 2015). In addition, a further study found shorter neuronal fibres bundles lengths in the left uncinate fasciculus of $A P O E \varepsilon 4+$ carriers related to severe deficits in semantic memory (Yasmin et al., 2008).

The comparison between APOE $\varepsilon 4+$ and APOE $\varepsilon 4$ - within centers revealed a trend in each subgroups of decreased FA and increased $M D$, axD and radD in the APOE $\varepsilon 4+$ groups. This evidence supports the claim that the overall effect is not due to center effects and that the investigation of indexes of WM microstructure at multicenter level, using different MRI protocols of acquisition, is feasible and lead to results previously replicated at monocentric level. However, previous studies showed that DTI scalar measurements are dependent on several factors, among them: the use of different b value, the number of diffusion directions and the voxel size. In particular, a study detecting any dependency of the FA values on the applied b-value, found significantly different mean FA values between the DTI acquisitions using a bvalue of $700 \mathrm{~s} / \mathrm{mm} 2$ and those using a b-value of $1000 \mathrm{~s} / \mathrm{mm} 2$ in the genu of right internal capsule and the anterior limb of left internal capsule (Bisdas et al., 2008). In our study most of the centre presented similar 
b-value. Center 4 displayed substantial higher FA values compared to the FA values of other Centers. Previous studies have showed that FA values are mainly affected by changes in the number of gradients and voxel resolution (Barrio-Arranz et al., 2015). In particular, high voxel size resulted in decreasing FA average. Center 4 shows a lower voxel size compared to other centers indicating a likely impact in increasing FA values. Moreover, a high number of gradient directions were shown to decrease FA (Jones, 2004). Our findings are in line with these previous results displaying decrease FA in the center with less gradient directions.

Despite the above results, findings on the effect of $A P O E \varepsilon 4$ in cognitively normal older individuals are still inconclusive, including studies describing no significant impact of the APOE \&4 allele on WM microstructure damages in middle-aged (Bendlin et al., 2010) and older (Nyberg and Salami, 2014) cognitive intact individuals. Furthermore, our results did not report any interaction between age and APOE as described in previous studies (Heise et al., 2011, Westlye et al., 2012), however contrasting results were reported (Adluru et al., 2014).

Some limitations of the present study need to be addressed. Firstly, due to the small sample size we cannot generalize our results. Secondly, due to the potentially limited anatomical specificity of the TBSS method (Bach et al., 2014), further analyses should be performed with additional techniques. For instance, the diffusion tensor imaging tractography dissection method (Catani et al., 2002) followed by a manual correction preformed by expert anatomists would allow to carry out more accurate measurements of white matter structures close to the cortical grey matter or subcortical nuclei such as the fornix and the uncinate (Acosta-Cabronero and Nestor, 2014). In addition, this manuscript does not investigate more potentially sensitive indices of white matter microstructure such as those from the NODDI model (Zhang et al., 2012) and from the advanced spherical deconvolution, such as the HMOA index (Dell'Acqua et al., 2013). Then, although center was included as a covariate of no interest in the group comparisons, our results might be affected by the different protocols of DTI acquisition used in each center. However, previous physical and clinical phantom studies based also on the EDSD database have revealed limited variability of DTI data when some minimal standards of acquisition are met (Landman et al., 2007, Teipel et al., 2011). Finally, we would like to underline that the multicenter nature of the EDSD study might not be the ideal condition to investigate the effect of APOE $\varepsilon 4$ genotype on the white matter microstructure, however at the same time the multicenter structure of the EDSD study allows the use of DTI among scanners and clinical settings. This is an essential aspect for the translation of imaging markers from the research bench to the clinical context.

In conclusion, this is the first multicenter study investigating a large spectrum of DTI indexes of WM microstructure. Despite the multicenter and not harmonized nature of EDSD DTI data, our findings support previous evidence regarding the impact of the APOE $\& 4$ genotype on WM integrity in cognitive intact older individuals. In particular, an early alteration of WM in the corpus callosum, in the cingulum, and in the inferior fronto-occipital and longitudinal fasciculi was found. These findings suggest that a reduction of WM tracts integrity may represent early pathological changes related to underlying AD pathology in healthy 
elderly individuals carrying APOE $\varepsilon 4$ (Hampel et al., 2010). In view of the heterogeneity of results previously described in the literature, our study adds information on possible causes of inter-individual WM heterogeneity that may be genetically determined by the presence of APOE genotype. Future studies should be conducted in even larger cohorts of subjects carrying APOE $\varepsilon 4$ alleles both at preclinical and prodromal level of $A D$ progression in order to further clarify the effect of APOE $\varepsilon 4$ on WM microstructure damages throughout the entire $A D$ continuum. 
Acknowledgments HH is supported by the AXA Research Fund, the Fondation Université Pierre et Marie Curie and the Fondation pour la Recherche sur Alzheimer, Paris, France. Ce travail a bénéficié d'une aide de l'Etat « Investissements d'avenir » ANR-10-IAIHU-06 (HH). The research leading to these results has received funding from the program "Investissements d'avenir" ANR-10-IAIHU-06 (Agence Nationale de la Recherche-10-IA Agence Institut Hospitalo-Universitaire-6) (HH). 


\section{References}

Acosta-Cabronero J, Nestor PJ (2014) Diffusion tensor imaging in Alzheimer's disease: insights into the limbic-diencephalic network and methodological considerations. Front Aging Neurosci 6:266.

Adluru N, Destiche DJ, Lu SY, Doran ST, Birdsill AC, Melah KE, Okonkwo OC, Alexander AL, Dowling NM, Johnson SC, Sager MA, Bendlin BB (2014) White matter microstructure in late middle-age: Effects of apolipoprotein E4 and parental family history of Alzheimer's disease. Neuroimage Clin 4:730-742.

Amlien IK, Fjell AM (2014) Diffusion tensor imaging of white matter degeneration in Alzheimer's disease and mild cognitive impairment. Neuroscience 276:206-215.

Bach M, Laun FB, Leemans A, Tax CM, Biessels GJ, Stieltjes B, Maier-Hein KH (2014) Methodological considerations on tract-based spatial statistics (TBSS). Neuroimage 100:358-369.

Barrio-Arranz G, de Luis-Garcia R, Tristan-Vega A, Martin-Fernandez M, Aja-Fernandez S (2015) Impact of MR Acquisition Parameters on DTI Scalar Indexes: A Tractography Based Approach. PLoS One 10:e0137905.

Bartzokis G (2004) Age-related myelin breakdown: a developmental model of cognitive decline and Alzheimer's disease. Neurobiol Aging 25:5-18; author reply 49-62.

Beaulieu C (2002) The basis of anisotropic water diffusion in the nervous system - a technical review. NMR Biomed 15:435-455.

Behrens TE, Berg HJ, Jbabdi S, Rushworth MF, Woolrich MW (2007) Probabilistic diffusion tractography with multiple fibre orientations: What can we gain? Neuroimage 34:144-155.

Bendlin BB, Ries ML, Canu E, Sodhi A, Lazar M, Alexander AL, Carlsson CM, Sager MA, Asthana S, Johnson SC (2010) White matter is altered with parental family history of Alzheimer's disease. Alzheimers Dement 6:394-403.

Bertram L, McQueen MB, Mullin K, Blacker D, Tanzi RE (2007) Systematic meta-analyses of Alzheimer disease genetic association studies: the AlzGene database. Nat Genet 39:17-23.

Bisdas S, Bohning DE, Besenski N, Nicholas JS, Rumboldt Z (2008) Reproducibility, interrater agreement, and age-related changes of fractional anisotropy measures at $3 T$ in healthy subjects: effect of the applied b-value. AJNR Am J Neuroradiol 29:1128-1133.

Boyles JK, Pitas RE, Wilson E, Mahley RW, Taylor JM (1985) Apolipoprotein E associated with astrocytic glia of the central nervous system and with nonmyelinating glia of the peripheral nervous system. J Clin Invest 76:1501-1513.

Brueggen K, Dyrba M, Barkhof F, Hausner L, Filippi M, Nestor PJ, Hauenstein K, Klöppel S, Grothe MJ, Kasper E, Teipel SJ (2015) Basal Forebrain and Hippocampus as Predictors of Conversion to Alzheimer's Disease in Patients with Mild Cognitive Impairment - A Multicenter DTI and Volumetry Study. J Alzheimers Dis 48:197-204.

Brueggen K, Grothe MJ, Dyrba M, Fellgiebel A, Fischer F, Filippi M, Agosta F, Nestor P, Meisenzahl E, Blautzik J, Frölich L, Hausner L, Bokde AL, Frisoni G, Pievani M, Klöppel S, Prvulovic D, Barkhof F, Pouwels PJ, Schröder J, Hampel H, Hauenstein K, Teipel S (2016) The European DTI Study 
on Dementia - A multicenter DTI and MRI study on Alzheimer's disease and Mild Cognitive Impairment. Neuroimage.

Burggren AC, Zeineh MM, Ekstrom AD, Braskie MN, Thompson PM, Small GW, Bookheimer SY (2008) Reduced cortical thickness in hippocampal subregions among cognitively normal apolipoprotein $\mathrm{E}$ e4 carriers. Neuroimage 41:1177-1183.

Catani M, Howard RJ, Pajevic S, Jones DK (2002) Virtual in vivo interactive dissection of white matter fasciculi in the human brain. Neuroimage 17:77-94.

Catani M, Jones DK, Donato R, Ffytche DH (2003) Occipito-temporal connections in the human brain. Brain 126:2093-2107.

Chalmers K, Wilcock G, Love S (2005) Contributors to white matter damage in the frontal lobe in Alzheimer's disease. Neuropathol Appl Neurobiol 31:623-631.

Chen K, Reiman EM, Alexander GE, Caselli RJ, Gerkin R, Bandy D, Domb A, Osborne D, Fox N, Crum WR, Saunders AM, Hardy J (2007) Correlations between apolipoprotein E epsilon4 gene dose and whole brain atrophy rates. Am J Psychiatry 164:916-921.

Chen Y, Chen K, Zhang J, Li X, Shu N, Wang J, Zhang Z, Reiman EM (2015) Disrupted functional and structural networks in cognitively normal elderly subjects with the APOE $\varepsilon 4$ allele.

Neuropsychopharmacology 40:1181-1191.

Chiang GC, Insel PS, Tosun D, Schuff N, Truran-Sacrey D, Raptentsetsang ST, Thompson PM, Reiman EM, Jack CR, Fox NC, Jagust WJ, Harvey DJ, Beckett LA, Gamst A, Aisen PS, Petersen RC, Weiner MW, Initiative AsDN (2011) Impact of apolipoprotein E4-cerebrospinal fluid $\beta$-amyloid interaction on hippocampal volume loss over 1 year in mild cognitive impairment. Alzheimers Dement 7:514-520.

Conturo TE, Lori NF, Cull TS, Akbudak E, Snyder AZ, Shimony JS, McKinstry RC, Burton H, Raichle ME (1999) Tracking neuronal fiber pathways in the living human brain. Proc Natl Acad Sci U S A 96:10422-10427.

Corder EH, Saunders AM, Strittmatter WJ, Schmechel DE, Gaskell PC, Small GW, Roses AD, Haines JL, Pericak-Vance MA (1993) Gene dose of apolipoprotein E type 4 allele and the risk of Alzheimer's disease in late onset families. Science 261:921-923.

Dell'Acqua F, Simmons A, Williams SC, Catani M (2013) Can spherical deconvolution provide more information than fiber orientations? Hindrance modulated orientational anisotropy, a true-tract specific index to characterize white matter diffusion. Hum Brain Mapp 34:2464-2483.

Donix M, Burggren AC, Suthana NA, Siddarth P, Ekstrom AD, Krupa AK, Jones M, Martin-Harris L, Ercoli LM, Miller KJ, Small GW, Bookheimer SY (2010a) Family history of Alzheimer's disease and hippocampal structure in healthy people. Am J Psychiatry 167:1399-1406.

Donix M, Burggren AC, Suthana NA, Siddarth P, Ekstrom AD, Krupa AK, Jones M, Rao A, Martin-Harris L, Ercoli LM, Miller KJ, Small GW, Bookheimer SY (2010b) Longitudinal changes in medial temporal cortical thickness in normal subjects with the APOE-4 polymorphism. Neuroimage 53:37-43. 
Douaud G, Jbabdi S, Behrens TE, Menke RA, Gass A, Monsch AU, Rao A, Whitcher B, Kindlmann G, Matthews PM, Smith S (2011) DTI measures in crossing-fibre areas: increased diffusion anisotropy reveals early white matter alteration in $\mathrm{MCl}$ and mild Alzheimer's disease. Neuroimage 55:880-890.

Du AT, Schuff N, Chao LL, Kornak J, Jagust WJ, Kramer JH, Reed BR, Miller BL, Norman D, Chui HC, Weiner MW (2006) Age effects on atrophy rates of entorhinal cortex and hippocampus. Neurobiol Aging 27:733-740.

Dyrba M, Barkhof F, Fellgiebel A, Filippi M, Hausner L, Hauenstein K, Kirste T, Teipel SJ, group Es (2015) Predicting Prodromal Alzheimer's Disease in Subjects with Mild Cognitive Impairment Using Machine Learning Classification of Multimodal Multicenter Diffusion-Tensor and Magnetic Resonance Imaging Data. J Neuroimaging 25:738-747.

Dyrba M, Ewers M, Wegrzyn M, Kilimann I, Plant C, Oswald A, Meindl T, Pievani M, Bokde AL, Fellgiebel A, Filippi M, Hampel H, Klöppel S, Hauenstein K, Kirste T, Teipel SJ, group Es (2013) Robust automated detection of microstructural white matter degeneration in Alzheimer's disease using machine learning classification of multicenter DTI data. PLoS One 8:e64925.

Dyrba M, Ewers, M., Plant, C., Barkhof, F., Fellgiebel, A., Hausner, L., Filippi, M., Kirste, T., Teipel, S. J. (2014) Prediction of prodromal AD in MCI subjects using multicenter DTI and MRI data and multiple kernels SVM: an EDSD study. Alzheimer's \& Dementia 10:P40.

Ewers M, Frisoni GB, Teipel SJ, Grinberg LT, Amaro E, Jr., Heinsen H, Thompson PM, Hampel H (2011a) Staging Alzheimer's disease progression with multimodality neuroimaging. Prog Neurobiol 95:535-546.

Ewers M, Sperling RA, Klunk WE, Weiner MW, Hampel H (2011b) Neuroimaging markers for the prediction and early diagnosis of Alzheimer's disease dementia. Trends Neurosci 34:430-442.

Felsky D, Voineskos AN (2013) APOE 4, aging, and effects on white matter across the adult life span. JAMA psychiatry 70:646-647.

ffytche DH, Catani M (2005) Beyond localization: from hodology to function. Philos Trans R Soc Lond B Biol Sci 360:767-779.

Filippini N, Ebmeier KP, Maclntosh BJ, Trachtenberg AJ, Frisoni GB, Wilcock GK, Beckmann CF, Smith SM, Matthews PM, Mackay CE (2011) Differential effects of the APOE genotype on brain function across the lifespan. Neuroimage 54:602-610.

Filippini N, Zarei M, Beckmann CF, Galluzzi S, Borsci G, Testa C, Bonetti M, Beltramello A, Ghidoni R, Benussi L, Binetti G, Frisoni GB (2009) Regional atrophy of transcallosal prefrontal connections in cognitively normal APOE epsilon4 carriers. J Magn Reson Imaging 29:1021-1026.

Firbank MJ, Blamire AM, Krishnan MS, Teodorczuk A, English P, Gholkar A, Harrison R, O'Brien JT (2007) Atrophy is associated with posterior cingulate white matter disruption in dementia with Lewy bodies and Alzheimer's disease. Neuroimage 36:1-7. 
Fischer FU, Scheurich A, Wegrzyn M, Schermuly I, Bokde AL, Klöppel S, Pouwels PJ, Teipel S, Yakushev I, Fellgiebel A (2012) Automated tractography of the cingulate bundle in Alzheimer's disease: a multicenter DTI study. J Magn Reson Imaging 36:84-91.

Fleisher AS, Chen K, Liu X, Ayutyanont N, Roontiva A, Thiyyagura P, Protas H, Joshi AD, Sabbagh M, Sadowsky CH, Sperling RA, Clark CM, Mintun MA, Pontecorvo MJ, Coleman RE, Doraiswamy PM, Johnson KA, Carpenter AP, Skovronsky DM, Reiman EM (2013) Apolipoprotein E $\varepsilon 4$ and age effects on florbetapir positron emission tomography in healthy aging and Alzheimer disease. Neurobiol Aging 34:1-12.

Fouquet M, Besson FL, Gonneaud J, La Joie R, Chételat G (2014) Imaging brain effects of APOE4 in cognitively normal individuals across the lifespan. Neuropsychol Rev 24:290-299.

Fox CJ, laria G, Barton JJ (2008) Disconnection in prosopagnosia and face processing. Cortex 44:9961009.

Gold BT, Johnson NF, Powell DK, Smith CD (2012) White matter integrity and vulnerability to Alzheimer's disease: preliminary findings and future directions. Biochim Biophys Acta 1822:416-422.

Hampel H, Frank R, Broich K, Teipel SJ, Katz RG, Hardy J, Herholz K, Bokde AL, Jessen F, Hoessler YC, Sanhai WR, Zetterberg H, Woodcock J, Blennow K (2010) Biomarkers for Alzheimer's disease: academic, industry and regulatory perspectives. Nat Rev Drug Discov 9:560-574.

Hampel H, Teipel SJ, Alexander GE, Horwitz B, Teichberg D, Schapiro MB, Rapoport SI (1998) Corpus callosum atrophy is a possible indicator of region- and cell type-specific neuronal degeneration in Alzheimer disease: a magnetic resonance imaging analysis. Arch Neurol 55:193-198.

Heise V, Filippini N, Ebmeier KP, Mackay CE (2011) The APOE $\varepsilon 4$ allele modulates brain white matter integrity in healthy adults. Mol Psychiatry 16:908-916.

Heise V, Filippini N, Trachtenberg AJ, Suri S, Ebmeier KP, Mackay CE (2014) Apolipoprotein E genotype, gender and age modulate connectivity of the hippocampus in healthy adults. Neuroimage 98:2330.

Hua X, Hibar DP, Lee S, Toga AW, Jack CR, Weiner MW, Thompson PM, Initiative AsDN (2010) Sex and age differences in atrophic rates: an ADNI study with $n=1368 \mathrm{MRI}$ scans. Neurobiol Aging 31:1463-1480.

Huang J, Friedland RP, Auchus AP (2007) Diffusion tensor imaging of normal-appearing white matter in mild cognitive impairment and early Alzheimer disease: preliminary evidence of axonal degeneration in the temporal lobe. AJNR Am J Neuroradiol 28:1943-1948.

Jack CR, Petersen RC, Xu YC, O'Brien PC, Waring SC, Tangalos EG, Smith GE, Ivnik RJ, Thibodeau SN, Kokmen E (1998) Hippocampal atrophy and apolipoprotein E genotype are independently associated with Alzheimer's disease. Ann Neurol 43:303-310.

Janowsky JS, Kaye JA, Carper RA (1996) Atrophy of the corpus callosum in Alzheimer's disease versus healthy aging. J Am Geriatr Soc 44:798-803. 
Jenkinson M, Bannister P, Brady M, Smith S (2002) Improved optimization for the robust and accurate linear registration and motion correction of brain images. Neuroimage 17:825-841.

Jones DK (2004) The effect of gradient sampling schemes on measures derived from diffusion tensor MRI: a Monte Carlo study. Magn Reson Med 51:807-815.

Jovicich J, Marizzoni M, Bosch B, Bartres-Faz D, Arnold J, Benninghoff J, Wiltfang J, Roccatagliata L, Picco A, Nobili F, Blin O, Bombois S, Lopes R, Bordet R, Chanoine V, Ranjeva JP, Didic M, GrosDagnac H, Payoux P, Zoccatelli G, Alessandrini F, Beltramello A, Bargallo N, Ferretti A, Caulo M, Aiello M, Ragucci M, Soricelli A, Salvadori N, Tarducci R, Floridi P, Tsolaki M, Constantinidis M, Drevelegas A, Rossini PM, Marra C, Otto J, Reiss-Zimmermann M, Hoffmann KT, Galluzzi S, Frisoni GB, PharmaCog C (2014) Multisite longitudinal reliability of tract-based spatial statistics in diffusion tensor imaging of healthy elderly subjects. Neuroimage 101:390-403.

Karch CM, Cruchaga C, Goate AM (2014) Alzheimer's disease genetics: from the bench to the clinic. Neuron 83:11-26.

Kerchner GA, Berdnik D, Shen JC, Bernstein JD, Fenesy MC, Deutsch GK, Wyss-Coray T, Rutt BK (2014) APOE \& 4 worsens hippocampal CA1 apical neuropil atrophy and episodic memory. Neurology 82:691-697.

Kilimann I, Grothe M, Heinsen H, Alho EJ, Grinberg L, Amaro Jr E, Dos Santos GA, da Silva RE, Mitchell AJ, Frisoni GB, Bokde AL, Fellgiebel A, Filippi M, Hampel H, Klöppel S, Teipel SJ (2014) Subregional Basal Forebrain Atrophy in Alzheimer's Disease: A Multicenter Study. J Alzheimers Dis.

Kljajevic V, Meyer P, Holzmann C, Dyrba M, Kasper E, Bokde AL, Fellgiebel A, Meindl T, Hampel H, Teipel S, group Es (2014) The epsilon4 genotype of apolipoprotein E and white matter integrity in Alzheimer's disease. Alzheimers Dement 10:401-404.

Kumar R, Chavez AS, Macey PM, Woo MA, Harper RM (2013) Brain axial and radial diffusivity changes with age and gender in healthy adults. Brain Res 1512:22-36.

Kumar R, Woo MA, Macey PM, Fonarow GC, Hamilton MA, Harper RM (2011) Brain axonal and myelin evaluation in heart failure. J Neurol Sci 307:106-113.

Landman BA, Farrell JA, Jones CK, Smith SA, Prince JL, Mori S (2007) Effects of diffusion weighting schemes on the reproducibility of DTI-derived fractional anisotropy, mean diffusivity, and principal eigenvector measurements at 1.5T. Neuroimage 36:1123-1138.

Lee YM, Ha JK, Park JM, Lee BD, Moon E, Chung YI, Kim JH, Kim HJ, Mun CW, Kim TH, Kim YH (2016) Impact of Apolipoprotein E4 Polymorphism on the Gray Matter Volume and the White Matter Integrity in Subjective Memory Impairment without White Matter Hyperintensities: Voxel-Based Morphometry and Tract-Based Spatial Statistics Study under 3-Tesla MRI. J Neuroimaging 26:144-149. 
Liu Y, Spulber G, Lehtimäki KK, Könönen M, Hallikainen I, Gröhn H, Kivipelto M, Hallikainen M, Vanninen $R$, Soininen $H$ (2011) Diffusion tensor imaging and tract-based spatial statistics in Alzheimer's disease and mild cognitive impairment. Neurobiol Aging 32:1558-1571.

Lockhart SN, DeCarli C (2014) Structural imaging measures of brain aging. Neuropsychol Rev 24:271-289.

Lu PH, Thompson PM, Leow A, Lee GJ, Lee A, Yanovsky I, Parikshak N, Khoo T, Wu S, Geschwind D, Bartzokis $G$ (2011) Apolipoprotein E genotype is associated with temporal and hippocampal atrophy rates in healthy elderly adults: a tensor-based morphometry study. J Alzheimers Dis 23:433-442.

Lyall DM, Harris SE, Bastin ME, Munoz Maniega S, Murray C, Lutz MW, Saunders AM, Roses AD, Valdes Hernandez Mdel C, Royle NA, Starr JM, Porteous DJ, Wardlaw JM, Deary IJ (2014) Alzheimer's disease susceptibility genes APOE and TOMM40, and brain white matter integrity in the Lothian Birth Cohort 1936. Neurobiol Aging 35:1513 e1525-1533.

Medina D, DeToledo-Morrell L, Urresta F, Gabrieli JD, Moseley M, Fleischman D, Bennett DA, Leurgans S, Turner DA, Stebbins GT (2006) White matter changes in mild cognitive impairment and AD: A diffusion tensor imaging study. Neurobiol Aging 27:663-672.

Morris JC, Roe CM, Xiong C, Fagan AM, Goate AM, Holtzman DM, Mintun MA (2010) APOE predicts amyloid-beta but not tau Alzheimer pathology in cognitively normal aging. Ann Neurol 67:122-131.

Nakai M, Kawamata T, Taniguchi T, Maeda K, Tanaka C (1996) Expression of apolipoprotein E mRNA in rat microglia. Neurosci Lett 211:41-44.

Nathan BP, Chang KC, Bellosta S, Brisch E, Ge N, Mahley RW, Pitas RE (1995) The inhibitory effect of apolipoprotein E4 on neurite outgrowth is associated with microtubule depolymerization. J Biol Chem 270:19791-19799.

Nichols TE, Holmes AP (2002) Nonparametric permutation tests for functional neuroimaging: a primer with examples. Hum Brain Mapp 15:1-25.

Nyberg L, Salami A (2014) The APOE $\varepsilon 4$ allele in relation to brain white-matter microstructure in adulthood and aging. Scand J Psychol 55:263-267.

O'Dwyer L, Lamberton F, Matura S, Scheibe M, Miller J, Rujescu D, Prvulovic D, Hampel H (2012) White matter differences between healthy young ApoE4 carriers and non-carriers identified with tractography and support vector machines. PLoS One 7:e36024.

Persson J, Lind J, Larsson A, Ingvar M, Cruts M, Van Broeckhoven C, Adolfsson R, Nilsson LG, Nyberg L (2006) Altered brain white matter integrity in healthy carriers of the APOE epsilon4 allele: a risk for AD? Neurology 66:1029-1033.

Pierpaoli C, Basser PJ (1996) Toward a quantitative assessment of diffusion anisotropy. Magn Reson Med 36:893-906.

Protas HD, Chen K, Langbaum JB, Fleisher AS, Alexander GE, Lee W, Bandy D, de Leon MJ, Mosconi L, Buckley S, Truran-Sacrey D, Schuff N, Weiner MW, Caselli RJ, Reiman EM (2013) Posterior cingulate glucose metabolism, hippocampal glucose metabolism, and hippocampal volume in 
cognitively normal, late-middle-aged persons at 3 levels of genetic risk for Alzheimer disease. JAMA Neurol 70:320-325.

Reiman EM, Chen K, Liu X, Bandy D, Yu M, Lee W, Ayutyanont N, Keppler J, Reeder SA, Langbaum JB, Alexander GE, Klunk WE, Mathis CA, Price JC, Aizenstein HJ, DeKosky ST, Caselli RJ (2009) Fibrillar amyloid-beta burden in cognitively normal people at 3 levels of genetic risk for Alzheimer's disease. Proc Natl Acad Sci U S A 106:6820-6825.

Reinvang I, Espeseth T, Westlye LT (2013) APOE-related biomarker profiles in non-pathological aging and early phases of Alzheimer's disease. Neurosci Biobehav Rev 37:1322-1335.

Reitz C, Brayne C, Mayeux R (2011) Epidemiology of Alzheimer disease. Nat Rev Neurol 7:137-152. Rimajova M, Lenzo NP, Wu JS, Bates KA, Campbell A, Dhaliwal SS, McCarthy M, Rodrigues M, Paton A, Rowe C, Foster JK, Martins RN (2008) Fluoro-2-deoxy-D-glucose (FDG)-PET in APOEepsilon4 carriers in the Australian population. J Alzheimers Dis 13:137-146.

Risacher SL, Shen L, West JD, Kim S, McDonald BC, Beckett LA, Harvey DJ, Jack CR, Weiner MW, Saykin AJ, (ADNI) AsDNI (2010) Longitudinal MRI atrophy biomarkers: relationship to conversion in the ADNI cohort. Neurobiol Aging 31:1401-1418.

Rose SE, McMahon KL, Janke AL, O'Dowd B, de Zubicaray G, Strudwick MW, Chalk JB (2006) Diffusion indices on magnetic resonance imaging and neuropsychological performance in amnestic mild cognitive impairment. J Neurol Neurosurg Psychiatry 77:1122-1128.

Ross ED (2008) Sensory-specific amnesia and hypoemotionality in humans and monkeys: gateway for developing a hodology of memory. Cortex 44:1010-1022.

Roussotte FF, Gutman BA, Madsen SK, Colby JB, Narr KL, Thompson PM, (ADNI) AsDNI (2014) Apolipoprotein $E$ epsilon 4 allele is associated with ventricular expansion rate and surface morphology in dementia and normal aging. Neurobiol Aging 35:1309-1317.

Rueckert D, Sonoda LI, Hayes C, Hill DL, Leach MO, Hawkes DJ (1999) Nonrigid registration using freeform deformations: application to breast MR images. IEEE Trans Med Imaging 18:712-721.

Ryan L, Walther K, Bendlin BB, Lue LF, Walker DG, Glisky EL (2011) Age-related differences in white matter integrity and cognitive function are related to APOE status. Neuroimage 54:1565-1577.

Saunders AM, Strittmatter WJ, Schmechel D, George-Hyslop PH, Pericak-Vance MA, Joo SH, Rosi BL, Gusella JF, Crapper-MacLachlan DR, Alberts MJ (1993) Association of apolipoprotein E allele epsilon 4 with late-onset familial and sporadic Alzheimer's disease. Neurology 43:1467-1472.

Schuff N, Woerner N, Boreta L, Kornfield T, Shaw LM, Trojanowski JQ, Thompson PM, Jack CR, Jr., Weiner MW, Alzheimer's Disease Neuroimaging I (2009) MRI of hippocampal volume loss in early Alzheimer's disease in relation to ApoE genotype and biomarkers. Brain : a journal of neurology 132:1067-1077.

Sherrington R, Rogaev El, Liang Y, Rogaeva EA, Levesque G, Ikeda M, Chi H, Lin C, Li G, Holman K, Tsuda T, Mar L, Foncin JF, Bruni AC, Montesi MP, Sorbi S, Rainero I, Pinessi L, Nee L, Chumakov I, Pollen D, Brookes A, Sanseau P, Polinsky RJ, Wasco W, Da Silva HA, Haines JL, Perkicak-Vance MA, Tanzi RE, Roses AD, Fraser PE, Rommens JM, St George-Hyslop PH 
(1995) Cloning of a gene bearing missense mutations in early-onset familial Alzheimer's disease. Nature 375:754-760.

Small GW, Siddarth P, Burggren AC, Kepe V, Ercoli LM, Miller KJ, Lavretsky H, Thompson PM, Cole GM, Huang SC, Phelps ME, Bookheimer SY, Barrio JR (2009) Influence of cognitive status, age, and APOE-4 genetic risk on brain FDDNP positron-emission tomography imaging in persons without dementia. Arch Gen Psychiatry 66:81-87.

Smith CD, Chebrolu H, Andersen AH, Powell DA, Lovell MA, Xiong S, Gold BT (2010) White matter diffusion alterations in normal women at risk of Alzheimer's disease. Neurobiol Aging 31:11221131.

Smith SM (2002) Fast robust automated brain extraction. Hum Brain Mapp 17:143-155.

Smith SM, Jenkinson M, Woolrich MW, Beckmann CF, Behrens TE, Johansen-Berg H, Bannister PR, De Luca M, Drobnjak I, Flitney DE, Niazy RK, Saunders J, Vickers J, Zhang Y, De Stefano N, Brady JM, Matthews PM (2004) Advances in functional and structural MR image analysis and implementation as FSL. Neuroimage 23 Suppl 1:S208-219.

Song SK, Sun SW, Ramsbottom MJ, Chang C, Russell J, Cross AH (2002) Dysmyelination revealed through MRI as increased radial (but unchanged axial) diffusion of water. Neuroimage 17:14291436.

Song SK, Yoshino J, Le TQ, Lin SJ, Sun SW, Cross AH, Armstrong RC (2005) Demyelination increases radial diffusivity in corpus callosum of mouse brain. Neuroimage 26:132-140.

Strittmatter WJ, Weisgraber KH, Huang DY, Dong LM, Salvesen GS, Pericak-Vance M, Schmechel D, Saunders AM, Goldgaber D, Roses AD (1993) Binding of human apolipoprotein E to synthetic amyloid beta peptide: isoform-specific effects and implications for late-onset Alzheimer disease. Proc Natl Acad Sci U S A 90:8098-8102.

Suthana NA, Krupa A, Donix M, Burggren A, Ekstrom AD, Jones M, Ercoli LM, Miller KJ, Siddarth P, Small GW, Bookheimer SY (2010) Reduced hippocampal CA2, CA3, and dentate gyrus activity in asymptomatic people at genetic risk for Alzheimer's disease. Neuroimage 53:1077-1084.

Sydykova D, Stahl R, Dietrich O, Ewers M, Reiser MF, Schoenberg SO, Möller HJ, Hampel H, Teipel SJ (2007) Fiber connections between the cerebral cortex and the corpus callosum in Alzheimer's disease: a diffusion tensor imaging and voxel-based morphometry study. Cereb Cortex 17:22762282.

Taylor JL, Scanlon BK, Farrell M, Hernandez B, Adamson MM, Ashford JW, Noda A, Murphy GM, Weiner MW (2014) APOE-epsilon4 and aging of medial temporal lobe gray matter in healthy adults older than 50 years. Neurobiol Aging 35:2479-2485.

Teipel SJ, Bayer W, Alexander GE, Bokde AL, Zebuhr Y, Teichberg D, Muller-Spahn F, Schapiro MB, Moller HJ, Rapoport SI, Hampel H (2003) Regional pattern of hippocampus and corpus callosum atrophy in Alzheimer's disease in relation to dementia severity: evidence for early neocortical degeneration. Neurobiol Aging 24:85-94. 
Teipel SJ, Grothe MJ, Filippi M, Fellgiebel A, Dyrba M, Frisoni GB, Meindl T, Bokde AL, Hampel H, Klöppel S, Hauenstein K (2014) Fractional Anisotropy Changes in Alzheimer's Disease Depend on the Underlying Fiber Tract Architecture: A Multiparametric DTI Study using Joint Independent Component Analysis. J Alzheimers Dis.

Teipel SJ, Reuter S, Stieltjes B, Acosta-Cabronero J, Ernemann U, Fellgiebel A, Filippi M, Frisoni G, Hentschel F, Jessen F, Klöppel S, Meindl T, Pouwels PJ, Hauenstein KH, Hampel H (2011) Multicenter stability of diffusion tensor imaging measures: a European clinical and physical phantom study. Psychiatry Res 194:363-371.

Teipel SJ, Stahl R, Dietrich O, Schoenberg SO, Perneczky R, Bokde AL, Reiser MF, Möller HJ, Hampel H (2007) Multivariate network analysis of fiber tract integrity in Alzheimer's disease. Neuroimage 34:985-995.

Teipel SJ, Wegrzyn M, Meindl T, Frisoni G, Bokde AL, Fellgiebel A, Filippi M, Hampel H, Klöppel S, Hauenstein K, Ewers M, group Es (2012) Anatomical MRI and DTI in the diagnosis of Alzheimer's disease: a European multicenter study. J Alzheimers Dis 31 Suppl 3:S33-47.

Tesseur I, Van Dorpe J, Bruynseels K, Bronfman F, Sciot R, Van Lommel A, Van Leuven F (2000) Prominent axonopathy and disruption of axonal transport in transgenic mice expressing human apolipoprotein E4 in neurons of brain and spinal cord. Am J Pathol 157:1495-1510.

Thompson PM, Mega MS, Woods RP, Zoumalan CI, Lindshield CJ, Blanton RE, Moussai J, Holmes CJ, Cummings JL, Toga AW (2001) Cortical change in Alzheimer's disease detected with a diseasespecific population-based brain atlas. Cereb Cortex 11:1-16.

Tijms BM, Kate MT, Wink AM, Visser PJ, Ecay M, Clerigue M, Estanga A, Garcia Sebastian M, Izagirre A, Villanua J, Martinez Lage P, van der Flier WM, Scheltens P, Sanz Arigita E, Barkhof F (2016) Gray matter network disruptions and amyloid beta in cognitively normal adults. Neurobiol Aging 37:154-160.

Tsao S, Gajawelli N, Hwang DH, Kriger S, Law M, Chui H, Weiner M, Lepore N (2014) Mapping of ApoE4 Related White Matter Damage using Diffusion MRI. Proc SPIE Int Soc Opt Eng 9039:90390H.

Westlye LT, Reinvang I, Rootwelt H, Espeseth T (2012) Effects of APOE on brain white matter microstructure in healthy adults. Neurology 79:1961-1969.

Xie S, Xiao JX, Gong GL, Zang YF, Wang YH, Wu HK, Jiang XX (2006) Voxel-based detection of white matter abnormalities in mild Alzheimer disease. Neurology 66:1845-1849.

Yasmin H, Nakata Y, Aoki S, Abe O, Sato N, Nemoto K, Arima K, Furuta N, Uno M, Hirai S, Masutani Y, Ohtomo K (2008) Diffusion abnormalities of the uncinate fasciculus in Alzheimer's disease: diffusion tensor tract-specific analysis using a new method to measure the core of the tract. Neuroradiology 50:293-299.

Yu JT, Tan L, Hardy J (2014) Apolipoprotein E in Alzheimer's disease: an update. Annu Rev Neurosci 37:79-100.

Zhang B, Xu Y, Zhu B, Kantarci K (2014) The role of diffusion tensor imaging in detecting microstructural changes in prodromal Alzheimer's disease. CNS Neurosci Ther 20:3-9. 
Zhang H, Schneider T, Wheeler-Kingshott CA, Alexander DC (2012) NODDI: practical in vivo neurite orientation dispersion and density imaging of the human brain. Neuroimage 61:1000-1016.

Zhang S, Chen Y, Liu Z, Zhang J, Li X, Cui R, Zhang Z (2015) Association of White Matter Integrity and Cognitive Functions in Chinese Non-Demented Elderly with the APOE $\varepsilon 4$ Allele. J Alzheimers Dis 48:781-791. 
Table 1. Acquisition parameters of DTI scans

\begin{tabular}{|c|c|c|c|c|c|c|c|c|c|}
\hline \multirow[t]{2}{*}{ Center } & \multirow{2}{*}{$\begin{array}{l}\text { Scanner } \\
\text { type }\end{array}$} & \multirow[t]{2}{*}{ Tesla } & \multicolumn{7}{|c|}{ DTI } \\
\hline & & & TR & TE & $\mathrm{Fa}$ & $\begin{array}{l}\text { Number of } \\
\text { diffusion } \\
\text { directions }\end{array}$ & b-values & Voxel size & Gap (mm) \\
\hline \multirow[t]{2}{*}{ CENTER 1} & Siemens & 1.5 & 8500 & 86 & 90 & 60 & 0,1000 & $2 \times 2 \times 2$ & 0 \\
\hline & Sonata & & & & & & & & \\
\hline \multirow[t]{2}{*}{ CENTER 2} & Siemens & 3.0 & 11,450 & 52 & 90 & 15 & 0,800 & $2 \times 2 \times 2$ & 0 \\
\hline & Trio & & & & & & & & \\
\hline \multirow[t]{2}{*}{ CENTER 3} & Siemen & 3.0 & 9300 & 102 & 90 & 12 & 0,1000 & $2 \times 2 \times 2$ & 0 \\
\hline & s Trio & & & & & & & & \\
\hline \multirow[t]{2}{*}{ CENTER 4} & Siemens & 3.0 & 8200 & 93 & 90 & 20 & 0,1000 & $1 \times 1 \times 2.4$ & 0.4 \\
\hline & Verio & & & & & & & & \\
\hline
\end{tabular}

$\mathrm{TR}=$ Repetition time (ms); TE = Echo time (ms); TI = Inversion time (ms); Fa = Flip angle (degrees). 
Table 2. Sociodemographic, global cognition and white matter microstructure parameters of 74 older adults cognitively normal individuals of the EDSD database.

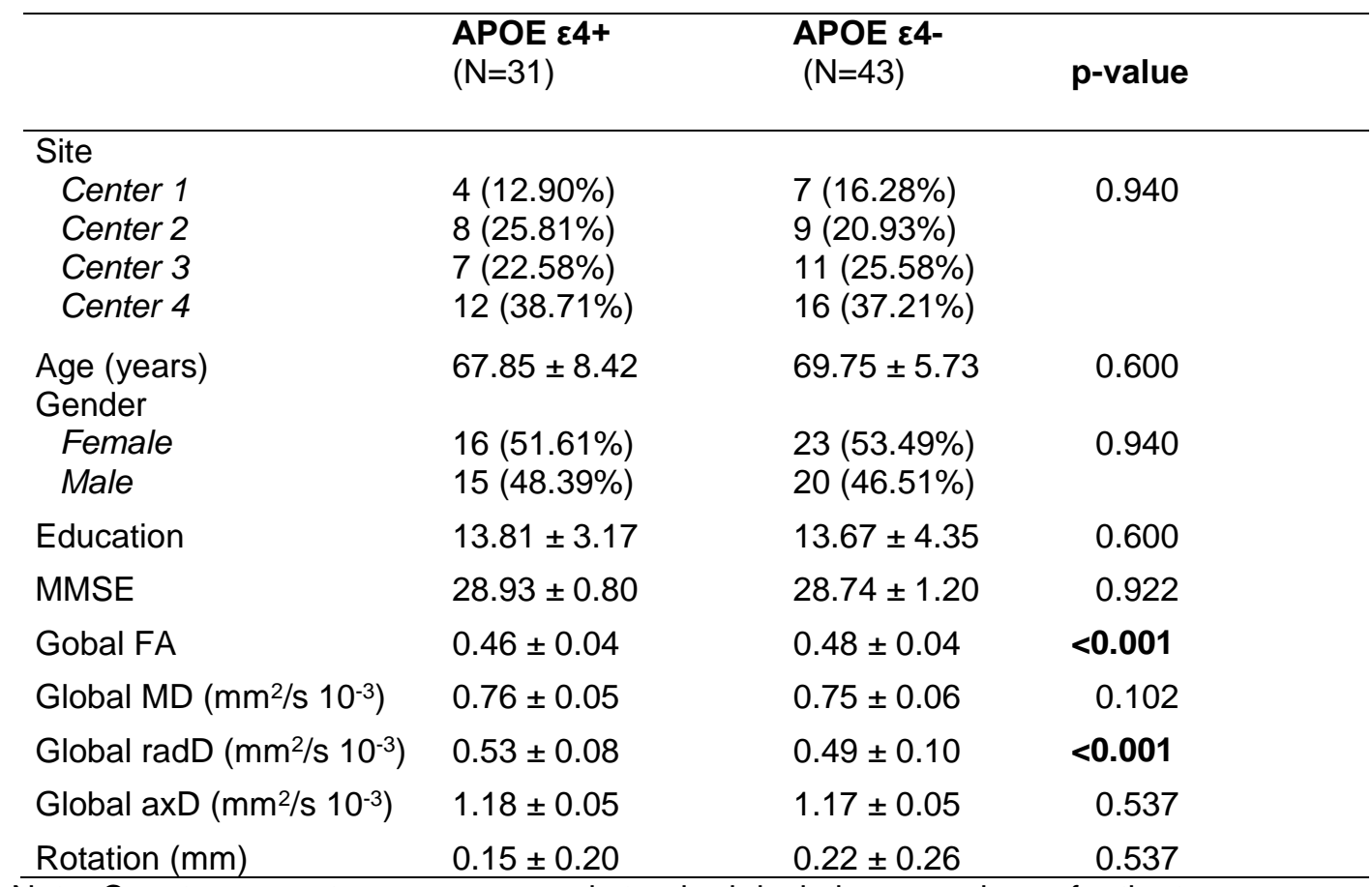

Note. Counts, percentages, means and standard deviations are shown for the two groups, as well as $p$ values, to indicate statistically significant group differences.

p-values are corrected for multiple testing using Benjamini-Hochberg method and adjusted for age, gender and center for DTI results. 
Table 3. Description of socio-demographic features, global cognitive performances and indexes of white matter integrity stratified by number of cases per center.

\begin{tabular}{|c|c|c|c|c|c|c|c|c|c|c|c|c|}
\hline & $\begin{array}{r}\text { APOE } \varepsilon 4+ \\
(\mathrm{N}=4) \\
\end{array}$ & $\begin{array}{l}\text { Center } 1 \\
\text { APOE } \varepsilon 4- \\
(\mathrm{N}=7) \\
\end{array}$ & p-value & $\begin{array}{r}\text { APOE } \varepsilon 4+ \\
(\mathrm{N}=8) \\
\end{array}$ & $\begin{array}{l}\text { Center } 2 \\
\text { APOE } \varepsilon 4- \\
(\mathrm{N}=9) \\
\end{array}$ & $p$-value & $\begin{array}{r}\text { APOE } \varepsilon 4+ \\
(\mathrm{N}=7) \\
\end{array}$ & $\begin{array}{l}\text { Center } 3 \\
\text { APOE } \varepsilon 4- \\
(N=11) \\
\end{array}$ & $p$-value & $\begin{array}{c}\text { Cent } \\
\text { APOE } \varepsilon 4+ \\
(\mathrm{N}=12) \\
\end{array}$ & $\begin{array}{l}4 \\
\text { APOE ع4- } \\
\quad(N=16)\end{array}$ & p-value \\
\hline Age (years) & $76.81 \pm 4.29$ & $74.30 \pm 5.49$ & 0.938 & $68.75 \pm 8.40$ & $67.56 \pm 5.03$ & 0.985 & $63.57 \pm 6.48$ & $68.27 \pm 7.32$ & 0.840 & $66.75 \pm 8.81$ & $70.00 \pm 4.07$ & 0.938 \\
\hline $\begin{array}{l}\text { Gender (F/M) } \\
\text { Female } \\
\text { Male }\end{array}$ & $\begin{array}{l}3(75.00 \%) \\
1(25.00 \%)\end{array}$ & $\begin{array}{l}5(71.43 \%) \\
2(28.57 \%)\end{array}$ & 0.985 & $\begin{array}{l}4(50.00 \%) \\
4(50.00 \%)\end{array}$ & $\begin{array}{l}6(66.67 \%) \\
3(33.33 \%)\end{array}$ & 0.938 & $\begin{array}{l}4(57.14 \%) \\
3(42.86 \%)\end{array}$ & $\begin{array}{l}4(36.36 \%) \\
7(63.64 \%)\end{array}$ & 0.938 & $\begin{array}{l}5(41.67 \%) \\
7(58.33 \%)\end{array}$ & $\begin{array}{l}8(50.00 \%) \\
8(50.00 \%)\end{array}$ & 0.938 \\
\hline Education (years) & $16.00 \pm 0.00$ & $17.00 \pm 3.21$ & 0.938 & $13.25 \pm 3.41$ & $13.78 \pm 7.16$ & 0.938 & $14.00 \pm 4.24$ & $13.09 \pm 3.73$ & 0.938 & $13.33 \pm 2.81$ & $12.56 \pm 2.37$ & 0.840 \\
\hline MMSE & $29.00 \pm 0.00$ & $28.86 \pm 1.46$ & 0.938 & $29.75 \pm 0.46$ & $28.89 \pm 1.62$ & 0.840 & $28.86 \pm 0.38$ & $29.18 \pm 0.75$ & 0.935 & $28.30 \pm 0.82$ & $28.31 \pm 1.01$ & 1.000 \\
\hline Gobal FA & $0.41 \pm 0.03$ & $0.43 \pm 0.01$ & 0.339 & $0.43 \pm 0.02$ & $0.44 \pm 0.02$ & 0.935 & $0.50 \pm 0.02$ & $0.51 \pm 0.02$ & 0.938 & $0.48 \pm 0.03$ & $0.52 \pm 0.02$ & 0.028 \\
\hline Global MD ( $\left.\mathrm{mm}^{2} / \mathrm{s} 10^{-3}\right)$ & $0.86 \pm 0.02$ & $0.85 \pm 0.03$ & 0.938 & $0.77 \pm 0.04$ & $0.76 \pm 0.02$ & 0.938 & $0.73 \pm 0.03$ & $0.73 \pm 0.03$ & 0.938 & $0.73 \pm 0.02$ & $0.71 \pm 0.03$ & 0.345 \\
\hline Global $\mathrm{radD}\left(\mathrm{mm}^{2} / \mathrm{s} 10^{-3}\right)$ & $0.66 \pm 0.03$ & $0.64 \pm 0.03$ & 0.840 & $0.58 \pm 0.04$ & $0.57 \pm 0.02$ & 0.938 & $0.52 \pm 0.04$ & $0.51 \pm 0.03$ & 1.000 & $0.47 \pm 0.07$ & $0.38 \pm 0.03$ & 0.007 \\
\hline 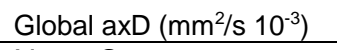 & $1.25 \pm 0.08$ & $1.22 \pm 0.06$ & 0.938 & $1.18 \pm 0.03$ & $1.14 \pm 0.02$ & 0.028 & $1.17 \pm 0.03$ & $1.18 \pm 0.05$ & 0.983 & $1.16 \pm 0.05$ & $1.16 \pm 0.03$ & 0.938 \\
\hline
\end{tabular}

Note. Counts, percentages, means and standard deviations are shown for the two groups, as well as p-values, to indicate statistically significant group differences.

p-values are corrected for multiple testing using Benjamini-Hochberg method. 


\section{Figure Captions}

Figure 1 Sample single-subject FA maps across different scanners for qualitative comparison. FA maps were selected from participant's non carrying APOE $\varepsilon 4$. For DTI acquisition parameters see Table 1.

Figure 2 Forest plots illustrating the distributions of DTI metrics within each group $(\varepsilon 4+/ \varepsilon 4-)$, both across and within each center. Diamonds indicate mean, Lower/ Upper Confidence Interval (Cl) at 95\%.

Figure 3 TBSS results: areas of decreased fractional anisotropy (FA) (red-yellow), in APOE $\varepsilon 4+v s$. APOE ع4-. Images are adjusted for scanner acquisition protocols, age and gender and for multiple comparisons at $p<0.05$. Numbers refer to $Z$ axis. Radiological convention: Right $(R)=$ Left $(L)$ Hemisphere, skeleton shown in green; $F W E=$ family-wise error.

Figure 4 Fractional Anisotropy maps adjusted for age and gender and stratified by center (each column), showing the contrast: APOE $\varepsilon 4->$ APOE $\varepsilon 4+$. Only significant results are depicted (results FWE corrected for Center 4 and uncorrected for Center 1,2,3). Numbers refer to $X$ axis in the upper row, $Y$ axis in the middle row and $Z$ axis in the lower row. Radiological convention: Right $(R)=$ Left $(L)$ Hemisphere, skeleton shown in green.

Figure 5 TBSS results: areas of increased Mean Diffusivity (MD) (red-yellow), in APOE $\varepsilon 4+v s$. APOE $\varepsilon 4-$. Images are corrected for age, gender and scanner acquisition protocols and for multiple comparisons at $p<0.05$. Numbers refer to $Z$ axis. Radiological convention: Right $(R)=$ Left $(L)$ Hemisphere, skeleton shown in green; $F W E=$ family-wise error.

Figure 6 Mean Diffusivity maps, stratified by center (each column), showing the contrast APOE $\varepsilon 4-<$ APOE $\varepsilon 4+$. Only significant results are depicted (results FWE corrected for Center 4 and uncorrected for Center $1,2,3)$. Numbers refer to $X$ axis in the upper row, $Y$ axis in the middle row and $Z$ axis in the lower row. Radiological convention: Right $(R)=$ Left $(L)$ Hemisphere, skeleton shown in green.

Figure 7 TBSS results: areas of increased Radial Diffusivity (radD) (red-yellow), in APOE $\varepsilon 4+v s$. APOE ع4-. Images are corrected for age, gender and scanner acquisition protocols and for multiple comparisons at $p<0.05$. Numbers refer to $Z$ axis. Radiological convention: Right $(R)=$ Left $(L)$ Hemisphere, skeleton shown in green; $F W E=$ family-wise error.

Figure 8 Radial Diffusivity maps, stratified by center (each column), showing the contrast APOE $\varepsilon 4-<$ APOE $\varepsilon 4+$. Only significant results are depicted. (results FWE corrected for Center 4 and uncorrected for 
Center 1, 2, 3). Numbers refer to $X$ axis in the upper row, $Y$ axis in the middle row and $Z$ axis in the lower row. Radiological convention: Right $(R)=$ Left $(L)$ Hemisphere, skeleton shown in green. 